\title{
Assessing Investor Biases Emerging from the Reading of Financial-Analyst Reports: Distortion of Information to Support Directional and Volatility-based Leanings
}

\author{
Simon J. Blanchard \\ Georgetown University \\ Kurt A. Carlson \\ College of William \& Mary
}

\begin{abstract}
Author Note
Simon J. Blanchard is Beyer Family Associate Professor of Marketing, Georgetown University; Kurt A. Carlson is Professor of Marketing, College of William \& Mary. Correspondence concerning this article should be addressed to Simon Blanchard, McDonough School of Business, Georgetown University, Washington, DC, 20057. Contact: sjb247@georgetown.edu. The authors would like to thank Sean Blair and James Angel for comments on previous versions of this manuscript. The authors would also like to thank Omar Al-Alami for providing industry expertise and insights.
\end{abstract}




\section{Assessing Investor Biases Emerging from the Reading of Financial-Analyst Reports: Distortion of Information to Support Directional and Volatility-based Leanings}

Retail investors increasingly have access to both platforms that allow for sophisticated trading strategies - those profit in ways other than by selling an owned stock after price increase - and to financial-analyst reports upon which to build investment strategies. Building on the predecisional distortion literature, we study how consumers of financial-analyst reports bias information to support emerging preferences, both directional and volatility-based trades. We then present the results of two experiments conducted with retail investors with high financial literacy asked to develop investment strategies based financial-analyst reports. We find that those tend to who develop preferences toward bearish trades (i.e., profits from a stock price decrease) tend to bias new information more strongly those who develop preferences toward bullish trades (i.e., profits from a stock price increase). We also show that those leaning toward volatility-based trades (i.e., profit from either small or large price movements) tend to evaluate information in a less biased way and those leaning toward directional trades (bullish or bearish).

Keywords: biases, predecisional distortion, biases, investor reports, financial decision making. 
Over the past few decades, the role of institutional investors (those who trade at such volume that they qualify for lower commissions and preferential treatment) has grown over time. In the 1950 s, less than $10 \%$ of the total US equity market cap belonged institutional investors; today it is more than $60 \%$, with approximately $80 \%$ of the S\&P and a slightly lower proportion for European stocks (e.g., S\&P Euro) is owned through institutional investments (McGrath 2017). Indeed, until the 1980s, most Americans relied on defined benefit plans, such as pensions and Social Security, for their retirement savings. In contrast, most Americans today rely on defined contribution plans, using IRA and 401k accounts to build their retirement nest eggs (Poterba, Venti, and Wise, 2007).

Whereas there is no doubt that institutional investors do most of the trading on the markets, retailer investors (i.e., non-professional consumers of trading firms) now have access to many of the same tools and platforms that institutional investors have used for decades.

Regulators and industry leaders are attempting to level the playing field between institutional investors and retail investors. For instance, the JOBS act from 2011 critically provided unaccredited retail investors access to both private equity offerings and crowdfunding investment opportunities that were previously only available to investors with substantial income and access (Albright, 2018). The CBOE (the premier options exchange platform) recently petitioned for a rule change with the SEC to prioritize retail investors in the trade queue, as they may not otherwise be able to execute trades at the same speeds. Today, $44 \%$ of US households possess shares of at least one mutual fund, $38 \%$ own a taxable trading account, and according to the Clearing House, 54\% of US banking consumers use a mobile app allowing for personal finance management, trading and investing. 
As access to sophisticated tools and trading strategies increased, both firms and retail investors changed their involvement in the market. Firms lowered costs to consumers, with many banks and brokers offering commission-free trades on stocks and ETFs (e.g., Schwab and Robinhood). Alternative outlets for dissemination of both technical and fundamental analyses have emerged. Previously only accessible through paid services (e.g., S\&P), are now readily accessible through numerous platforms with free recommendations (e.g., Seeking Alpha and Zacks Investment Research) or indexes of analyst reports (e.g., Yahoo Finance!). New technological platforms and brokers have emerged to educate retail investors with little investment literature to engage with the market via complex vehicles, even including options trading (e.g., Tastyworks and Tradezero America). Such platforms allow retail investors with little financial expertise or stability to perform complex trades beyond buying and selling an underlying (i.e., a stock or fund), but also to sell an underlying they do not own (e.g., shorting a stock) and buying or selling options contracts.

Given this democratization process with access to additional investment options and analyst reports to ground their decisions, it is important to understand how it will influence retail investors' decisions. This transition, which has provided people more flexibility and labor mobility, has also provided greater control over retirement savings — control which requires greater individual involvement in the financial decision-making process (Lusardi 2012). With greater control comes the potential for one's own bias to exert greater influence on one's own investment decisions. It is well known that investors bias new information based on their prior beliefs (Hirst, Koonce, \& Simko 1995; Moore et al. 1999) and on the opinion of other investors (Gonzalez 1994). Blair (2019) finds that personal control threats (e.g., fall of Lehmann brothers) increase preference for fluent stimuli (e.g., stocks with easy-to-pronounce ticker symbols) that 
help promote a sense of structure. One important source of information acquisition that has led to biases is that of financial-analyst research reports - which we see as more readily available. In a classic example, Hirst, Koonce and Simko (1995) showed that investor behavior is unduly influenced not only by the content of the report (strength of arguments), but also by the source of the research report (an analyst with or without a relationship with the company). They found that when the recommendation was negative, especially coming from an investment banking analyst (for which a negative recommendation is unusual), investors were more influenced by strong than weak claims.

Before the democratization of institutional trading strategies, retail investors could generally only create trades that profit when the price of an underlying (i.e., stock) increased in price (e.g., buying a stock and sell it at a higher price). However, positions which profit when the price of the underlying decreases in price (e.g., shorting a stock) or with changes in volatility (e.g., buying or selling mixed-options such as a straddle or strangle). Little is known about how investors bias information in analyst reports to support such emerging preferences. In the present research, we build on the literature on predecisional distortion and the stepwise evolution of preference method (Russo, Medvec \& Meloy, 1996; see Dekay, 2015) to study how consumers of financial-analyst reports bias information to support emerging preferences even for investment vehicles for which they do not carry a position. To do so, we extend the multi-option stepwise evolution of preference method (Blanchard, Carlson and Meloy 2015; Dekay et al. 2015) to accommodate option sets wherein biases favoring one alternative does not necessarily disfavor the others. Then, we present the results from two studies with panels of retail investors qualified for financial literacy using the same instruments used by researchers and practitioners alike. We show that individuals who, while reading an analyst report, lean toward executing a trade that 
profits with a stock price decrease tend to bias new information from reports more strongly than individuals who develop a leaning that profits from a stock price increase. Moreover, we show that those who develop leanings toward executing trades that profit from either small or large price movements tend to evaluate information in a less biased way.

\section{THEORETICAL DEVELOPMENT}

Leaders and Predecisional Distortion

The tendency for people to draw conclusions consistent with their beliefs, choices, and preferences is an extremely robust phenomenon in human judgment and decision making (Bacon, 1939; Nickerson, 1998; Thurstone, 1924). This tendency is supported by a variety of mechanisms that include selective exposure to information (Koriat, Lichtenstein \& Fishoff, 1980) and biased interpretation of new information (Lord, Ross \& Lepper, 1979; Westen et al., 2006). In recent years, studies have established that the biased interpretation of information occurs predecisionally (i.e., during a choice process) to support an emerging preference for the alternative that is seen as most promising early in the choice process (Brownstein, 2003; Dekay, 2015; Russo, Medvec \& Meloy, 1996).

Research shows that decision-makers predecisionally enhance consistency between units of information by distorting new information to support the leading alternative, thereby increasing its chances of being selected even if doing so undermines choice quality (Carlson, Meloy, \& Russo, 2006; Russo, Carlson, \& Meloy, 2006). Importantly, leading alternatives seem to emerge automatically (Carlson \& Pearo, 2004) and the biased interpretation of information that helps keep them leading is robust across a wide variety of choice contexts (Brownstein, Read \& Simon, 2004; Russo, Carlson, \& Meloy, 2008) including risky choice (Dekay, Patino- 
Echeverri, Fischbeck, 2009; Miller et al., 2013). A multitude of studies has now established that when new data conflicts with the tentative preference in a choice process, it is generally the tentative preference and not the unbiased data that survives (Brownstein, 2003).

Most research to date has studied predecisional distortion by examining how the emerging preference for one alternative causes decision-makers to bias the interpretation or evaluation of new information about the alternatives under consideration. The most common approach is to examine how decision-makers evaluate a new attribute in a binary choice as a function of which alternative is leading. By using an evaluation scale that is anchored on opposite ends by the alternatives and calculating the signed deviation of each evaluation (where the sign is dictated by whichever option is leading and the deviation is from its unbiased average), one can compute a measure of distortion that estimates how much each decision-maker biased their evaluations in the direction of whichever alternative (e.g., option A versus option B) was leading.

An alternative to this traditional approach is to use separate evaluation scales for each alternative. This approach (Blanchard, Carlson \& Meloy, 2014) allows researchers to examine choices involving more than two alternatives while also making it possible to differentiate distortion favoring the leader from distortion disfavoring the non-leading alternatives (i.e., antitrailer distortion). ${ }^{1}$ Research using these two different distortion mechanisms (Blanchard, Carlson \& Meloy, 2014; see also Dekay et al., 2014, Miller, 2014) has found that pro-leader and anti-trailer distortion differ based on (a) which alternative is leading (e.g., Chaxel, 2015), (b) the decision domain (e.g., Nurek, Kostopoulou \& Hagman, 2014), (c) the strength of one's memory

\footnotetext{
${ }^{1}$ This symmetry is also expected in the context of single-option choices where individuals can either choose or "not choose" (e.g., Bond et al. 2007).
} 
for the information (Dekay et al., 2014), and (d) the size of the choice consideration set (Blanchard, Carlson \& Meloy, 2014).

Investment Options and Predecisional Distortion

In a typical application of the predecisional distortion paradigm to investments, an investor would be choosing between two stocks and be presented attribute information for each of the two options (Stocks A and B). The task would be structured such that the investor begins by reading, for both stocks, the first narrative attribute (e.g., the analyst note). The investor would be asked to evaluate whether the analyst note favors Stock A (1) or Stock B (9) and develop a leaning regarding which is the better stock to invest (i.e., tentative preference or leader). Then, predecisional distortion is measured by assessing whether the tentative preference that emerged after the first attribute unduly influences the relative evaluation of the next attribute (e.g., economic moat) in favor of the alternative that is tentatively leading. In such a setting, distortion that positively biases information about Stock A (e.g., seeing it more likely to increase in price) does the double duty of the appeal of Stock A is chosen while reducing the appeal of Stock B. To date, both the single evaluation and the alternative-specific evaluation scale approaches to measuring distortion have been applied exclusively to choices where decisionmakers are tasked with selecting one alternative from two or more alternatives (for an exception, see Bond et al., 2007). A consequence of using this bipolar evaluation scale is that prior research cannot quantify distortion when biasing the evaluation of information can simultaneously benefit more than one alternative - or one product with multiple investment strategies.

To illustrate how this would manifest under the reading a financial-analyst report, consider an investor who is evaluating a given underlying (i.e., stock) and considering the 
actions he or she could take. After developing a leaning, the investor is then presented the following new information from an analyst's report (we refer to such paragraphs as narrative attributes; see Appendix A):

While Morgan Stanley reported disappointing third-quarter numbers, we still believe in the company's core strategy and that there's optionality in regard to the company's fixed-income trading business and capital returns. The company's Institutional Securities and Investment Management segments led the company to a $16 \%$ decrease in net revenue from the previous year, excluding debt valuation adjustments. The underperforming revenue lines were similar to other investment banking firms with fixed-income trading, underwriting, and revenue tied to investment performance being the primary culprits. The wealth management segment remained fairly steady with a net revenue decline of only 4\%. We don't anticipate making a material change in our fair value estimate for narrow-moat Morgan Stanley, and believe that its shares are starting to look attractive.

In this example, the investor is considering only a single stock—namely, Morgan Stanley. In this case, despite evaluating a single stock, there are several positions that an investor can take: (1) betting the stock's price will increase, (2) betting its price will decrease, (3) betting its price will not change, and (4) betting its price will change without expectation of if it will go either up or down. These are the four most common trading strategies a retail investor with access to options or margin accounts can take on any publicly traded stock. As any of these four actions becomes a preference, then subsequent attribute information (e.g., economic moat) could be evaluated to support it. But what would the pattern of distortion look like? We illustrate the profit charts and supporting predecisisional distortion patterns for each, in Figure 1. 


\section{FIGURE 1 - Four Types of Investment Strategies*}

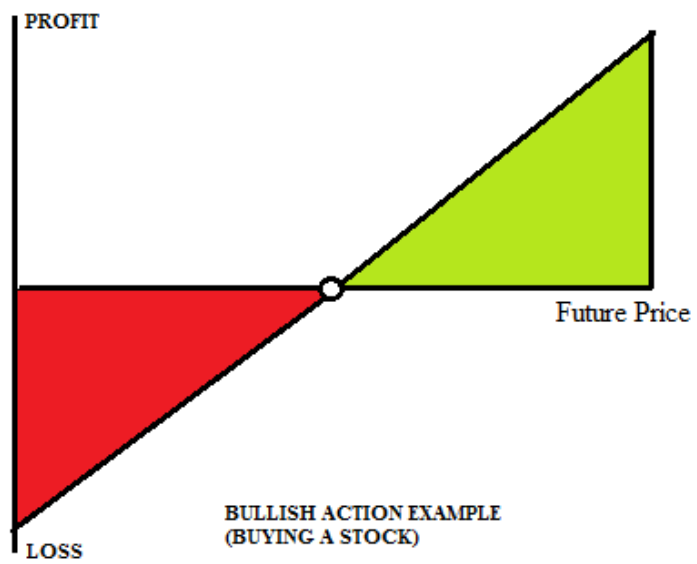

Possible information bias for supporting action leaning.

a) Subsequent Bullish information judged as more positive

b) Subsequent Bearish information judged as less negative

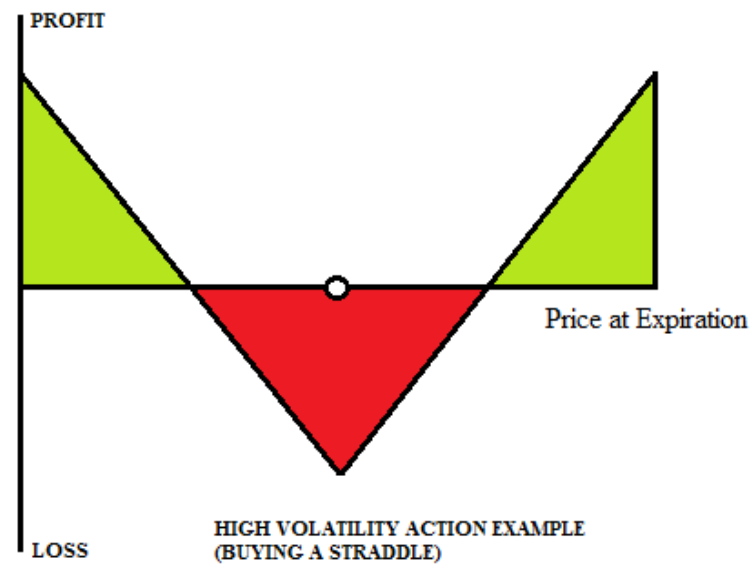

Possible information bias for supporting action leaning:

a) Subsequent Bullish information judged as more positive

b) Subsequent Bearish information judged as more negative

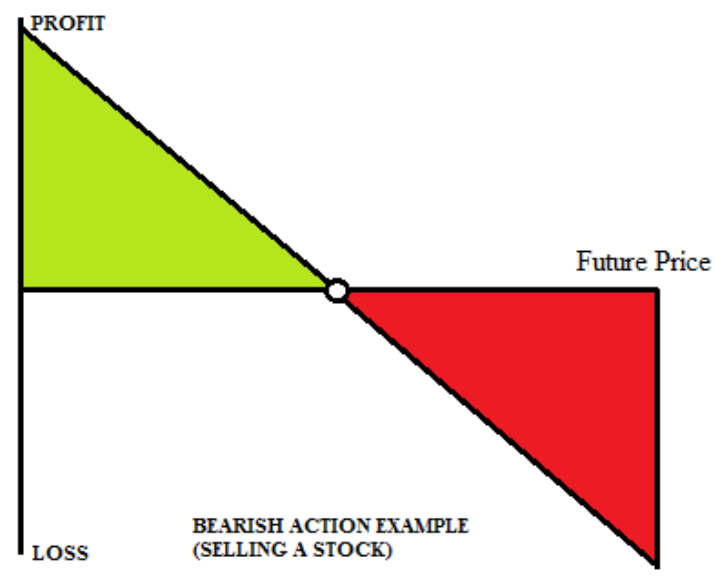

Possible information bias for supporting action leaning:

a) Subsequent Bullish information judged as less positive

b) Subsequent Bearish information judged as more negative

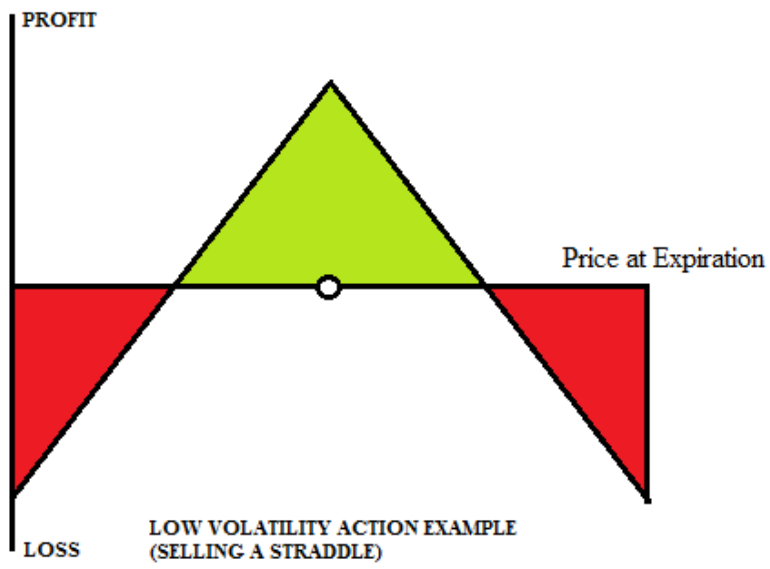

Possible information bias for supporting action leaning:

a) Subsequent Bullish information judged as less positive

b) Subsequent Bearish information judged as less negative

* Note: The knot in each panel indicates the stock price at which the action is taken. Zones in green indicate regions in which a price movement would result in a profit, and zones in red indicate regions in which a price movement would result in a loss. 
Consider a tentative preference for a position that profits if the stock's price drops (option 2), then distortion to support this leaning would take the form of biasing new information about the stock to make the stock seem less appealing than it would be seen objectively. In contrast, a tentative preference for a position that profits if the stock's price changes (either up or down; option 3) but takes a loss if the stock's price remains stable, then distortion to support this leaning would take the form of biasing positive information to be more positive than it really is and/or of biasing negative information about the stock to be more negative than it really is.

Seeing arguments for both a potential increase or decrease is indeed the sort of pattern that would support a strategy that hinges on volatility.

We thus believe that when applying the distortion paradigm to a single alternative stock with different potential actions, one must carefully decide on describing the possible actions. Herein, we use common trading strategies to define four broad potential actions. The investor could decide between taking a bullish action (i.e., one that profits if the stock price increases, for instance buying a stock), a bearish action (i.e., one that profits if the stock price decreases, for instance shorting a stock), a high-volatility action (i.e., one that profits if the stock price either increases or decreases significantly, for instance buying a straddle), or a low-volatility action (i.e., one that profits if the stock price neither increases nor decreases significantly, for instance selling a straddle).

\section{EXPERIMENT 1 - PREDECISIONAL DISTORTION IN FINANCIAL REPORTS}

Participants and Procedures

Financial Literacy Qualification. We wanted to limit participation in this experiment to individuals who had sufficient financial literacy and understanding of the advanced retail 
investment strategies previously discussed. To this end, we first administered the Advanced Financial Literacy scale introduced by van Rooij, Lusardi, and Alessie (2011) to an online panel (Amazon Mechanical Turk) as a pre-qualification task. The scale (see Appendix B for the items in the scale) has been shown to be significantly related to the understanding of the benefits of risk diversification, time value of money, economics education, and to be an important predictor of stock ownership and search for information regarding financial investments. It is the same scale used as part of FINRA Foundation's financial capability report (e.g., Mottola 2015) and countless academic publications.

We recruited 1,896 participants located in the United States to take a set of qualifying instruments in exchange for $\$ 0.15$. Participants answered the financial literacy questions, provided some demographic information (age, gender, education), and then indicated if they own an investment account (e.g., trading stocks, ETFs, indexes, futures), a savings account, a checking account, credit cards, and/or a retirement investment account (e.g., 401(k), IRA, Roth IRA, 403(b)). Participants who correctly answered 8 or more of the 11 advanced financial literacy questions and reported owning an investment account were qualified to become part of the investment choice experiment. Of the 1,841 who took the qualification survey, 403 qualified. Those who qualified were more likely to have a savings account $\left(93.5 \%\right.$ vs. $82.1 \% ; \chi^{2}(1)=$ $31.26, p<.01)$ and they were more likely to have a retirement account $(79.9 \%$ vs $38.8 \%$; $\left.\chi^{2}(1)=206.581, p<.01\right)$ than those who did not qualify. Those who qualified were also more likely to have completed a post-graduate degree $\left(22.1 \%\right.$ vs $\left.9.5 \% ; \chi^{2}(1)=46.24, p<.01\right)$, more likely to be male $\left(64.3 .5 \%\right.$ vs $\left.44.5 \% ; \chi^{2}(1)=48.86, p<.01\right)$, and were slightly older (average age: 35.93 years vs. 32.44 years; $t(1776)=5.77, p<.01$ ) than those who did not qualify. All 403 participants who qualified were immediately offered the opportunity to 
participate in a follow-up survey on investments in exchange for an additional payment. Of those invited to take the follow-up survey, 394 opted to do so. These 394 participants were randomly assigned to either the control condition, where they evaluated one of the six narrative attributes ( $\$ 0.20$ payment; $\mathrm{N}=204$ ) or to the investment choice condition ( $\$ 1$ payment; $\mathrm{N}=190$ ).

Stimuli and Measures

Participants evaluated information from a financial-analyst report on Morgan Stanley to help them make a hypothetical investment decision. First, participants were told they would read a financial-analyst about a company currently on the stock market and that they would be asked to provide their leaning as to what the stock price will be in the future. Second, participants read a company overview (taken from the investor report) that read: "Morgan Stanley is a global investment bank whose history, through its legacy firms, can be traced back to 1924. The company has institutional securities, wealth management, and asset management segments and more than 55,000 employees. The company derives about $30 \%$ of its total revenue outside the Americas." After this, participants read six pieces of information (attributes) from the financialanalyst report: Analyst Note, Investment Thesis, Economic Moat, Valuation, Risk, and Management. The attributes, each of which was shown to participants on a separate screen, were presented in the same order in which they appeared in the report (i.e., in the order listed above) that was taken from Morningstar (see also Lewis and Gill 2016). The entire analyst report can be found in Appendix A.

After reading each attribute, but before progressing to the next in the sequence, participants rated the information for its bullishness and bearishness by indicating agreement with the following two statements: "Using only the information on this page, I believe there is 
compelling evidence for the stock price to go up," (bullishness) and "I believe there is compelling evidence for the stock price to go down," (bearishness). Responses to each were captured on 7-point Likert scales, anchored by $1=$ "strongly disagree" and 7 = "strongly agree." Participants also indicated their leaning by responding to the following question: "Based on all the information you've seen so far in this report, which best reflects your belief about the way the stock price will move?" Response options were: 1) "I believe the stock will go up, from its current price," 2) "I believe the stock will go down, from its current price," 3) "I believe the stock will move significantly from its current price. The stock could move up, or it could move down, but it will move," and 4) "I believe the stock will not move significantly from its current price." Each participant selected one (and only one) leaning after each attribute.

After providing these three responses for all six attributes, participants were shown a final screen where they made a final investment choice by selecting one of the following five options: 1) buy the stock (take a bullish position), 2) sell the stock (take a bearish position), 3) a buy a straddle (take a non-neutral position), 4) sell a straddle (take a neutral position), and 5) do not take any position in the stock. Participants then indicated their confidence in their choice using a 100-point sliding scale anchored by $0=$ "not confident at all" and $100=$ "extremely confident." Finally, participants answered questions regarding their financial holdings, financial experience, gender, and age.

We note that the approach herein builds on the stepwise evolution of preference (SEP) approach commonly used in distortion research, which has shown to be a valid way of assessing pre-choice bias (see Chaxel, Russo and Kerimi 2013). The method follows that to Blanchard, Carlson, and Meloy (2014), expanding the measurement of tentative preferences with four separation options to accommodate multi-option choices (see also Dekay et al. 2014) and 
replaces a bipolar attribute evaluation scale (e.g., 1-favors A, 9-favors B). In Blanchard et al. (2014), the attribute evaluation scales were separated to have one per option. For example, three options choice would have three questions, each measuring whether the attribute evaluation is appealing for the choice of the alternative (e.g., 1- very unappealing for A, 9- very appealing for A). In the present work, we do not need four different appeal items to capture the patterns of distortion consistent with the four emerging preferences. Instead, we use two measures for the evaluation that the narrative attribute could support a bullish investment thesis and an evaluation that the narrative attribute could support a bearish investment thesis.

\section{Calculating Predecisional Distortion}

Normatively, the interpretation of bullishness or bearishness of any attribute should be independent of the leaning held by prospective investors before they read the narrative attribute. In contrast to this, we expected that such interpretations would indeed be influenced by respondents' leanings.

Control Condition. To determine whether the interpretation of an attribute was biased toward a leaning, bullish and bearish baselines were established for each attribute. To obtain these baselines, participants in a separate control condition were told they would be presented information about a company currently on the stock market and were given the same overview of Morgan Stanley. They then read one (and only one) of the six narrative attributes presented to the participants in the choice condition and interpreted the information using the same 7-point bullishness and bearishness scales (see above). Given that these evaluations were obtained from control participants who did not have any leaning, their responses could not have been influenced by a leaning. Thus, we obtained unbiased bullishness and bearishness evaluations 
from the responses of these control participants by using the mean evaluation of each attribute across all control participants who interpreted it.

Calculating the Effect of Leanings on Evaluations. First, let $U_{j}\left(D_{j}\right)$ be the leaning-free bullish and bearish evaluations of attribute $j(j=1, \ldots, 6)$ obtained by averaging the evaluations made by all the participants in the control condition who read and evaluated attribute $j$. Second, for participants in the choice condition, let $E U_{j}^{i}\left(E D_{j}^{i}\right)$ be individual $i$ 's $(i=1, \ldots, N)$ bullish (bearish) evaluation for attribute $j$. Third, let $L_{j k}^{i}$ be an indicator set at 1 if individual $i$ 's leaning after reading narrative attributes up to $j-1$, corresponds to a bullish, bearish, high volatility and low volatility leanings, respectively $(k \in\{B U, B E, H V, L V\})$,

If an individual $i$ 's leaning (based on seeing information up to attribute $j-1$ ) has no effect on the interpretation of subsequent narrative attributes, then his/her interpretation of the next narrative attribute $E U_{i j}$ should be relatively close to that of participants in the control condition $U_{j}$.

When looking at the interpretation of narrative attributes, the difference $D_{P o s, j}^{i}\left(D_{P o s, j}^{i}=\right.$ $\left.E U_{j}^{i}-U_{j}\right)$ is one of our two focal measures. If $D_{P o s, j}^{i}>0$, then the individual judged the narrative attribute as providing more compelling evidence for a bullish action than participants in the control condition. In contrast if $D_{P o s, j}^{i}<0$, then the individual judged the attribute as provided less compelling evidence for a bullish action than participants in the control condition.

Likewise, the difference $D_{N e g, j}^{i}\left(D_{N e g, j}^{i}=E D_{j}^{i}-D_{j}\right)$ is our second focal measure. If $D_{N e g, j}^{i}>0$, then the individual judged the narrative attribute as providing more compelling bearish evidence than participants in the control condition. Further, $D_{N e g, j}^{i}<0$ then the individual judged the narrative attribute as providing less compelling bearish evidence than 
participants in the control condition. Then, to consider how leanings influence the difference in subsequent evaluations, we can express the difference via the following equation:

$$
\bar{D}_{\text {Pos }}^{i}=\alpha+\sum_{k=1}^{K} \bar{L}_{k}^{i} \beta_{U, k}+v_{i}+\bar{\epsilon}_{i}
$$

Where $\bar{D}_{P o s}^{i}=\sum_{j=2}^{J} \frac{D_{P o s, j}^{i}}{(J-1)}, \bar{L}_{k}^{i}=\sum_{j=1}^{J-1} \frac{L_{j, k}^{i}}{(J-1)}$, and $\bar{\epsilon}_{i}=\sum_{j=2}^{J} \frac{\epsilon_{i j}}{(J-1)}$, and where $v_{i}$ is an individual specific error term, and $\epsilon_{i j}$ is a narrative attribute and individual-level error term. In such a specification, $\beta_{U, k}$ represents a between-subject biasing effect of the bullish evaluation due to leaning $k$ when making the evaluations. $\beta_{U k}$ (and $\alpha$ ) can be estimated via ordinary least squares $^{2}$. Likewise, for bearish evaluations, we can express the difference via the following equation:

$$
\bar{D}_{N e g}^{i}=a+\sum_{k=1}^{K} \bar{L}_{k}^{i} \beta_{D, k}+\delta_{i}+\bar{\gamma}_{i},
$$

where $\bar{D}_{N e g}^{i}=\sum_{j=2}^{J} \frac{D_{N e g, j}^{i}}{(J-1)}$, and $\bar{\gamma}_{i}=\sum_{j=2}^{J} \frac{\gamma_{i j}}{(J-1)}$, and where $\delta_{i}$ is an individual-specific error term, and $\gamma_{i j}$ is a narrative attribute $\&$ individual level error term. In such a specification, $\beta_{D k}$ represents the between-subject biasing effect on the bearish evaluation due to having a leaning $k$. $\beta_{D k}($ and $\alpha$ ) can also be estimated via ordinary least squares.

\section{Results}

Attribute Baselines. The average bullishness and bearishness evaluations for each attribute from participants in the control condition are presented in Table 1. Notice that the average bullishness evaluation across the six attributes is 4.48 , suggesting that control

\footnotetext{
${ }^{2}$ Given that we have four possible leaning, $L_{j, k}^{i}$ is binary coded such that only 3 out of the $4 L_{j, k}^{i}$ are entered into the model and $\alpha$ provides the focal effect for the default (non-entered) leaning.
} 
participants saw the six attributes as slightly bullish. Consistent with this, the average bearishness evaluation was 3.51, indicating that participants (on average) disagreed with the attributes supporting a bearishness view of the stock.

TABLE 1 - Experiment 1: Attribute descriptive statistics from the control condition*

Std.

\begin{tabular}{rlrrr}
$\mathbf{j}$ & Attribute & N & Mean & Deviation \\
\hline 1 & Analyst Note - Bullish evaluation $\left(U_{1}\right)$ & 33 & 3.76 & 1.542 \\
& Analyst Note - Bearish evaluation $\left(D_{1}\right)$ & 33 & 4.36 & 1.365 \\
2 & Investment Thesis - Bullish evaluation $\left(U_{2}\right)$ & 34 & 4.68 & 1.532 \\
& Investment Thesis - Bearish evaluation $\left(D_{2}\right)$ & 34 & 3.06 & 1.434 \\
3 & Economic Moat - Bullish evaluation $\left(U_{3}\right)$ & 34 & 5.38 & .922 \\
& Economic Moat - Bearish evaluation $\left(D_{3}\right)$ & 34 & 2.91 & 1.379 \\
4 & Valuation - Bullish evaluation $\left(U_{4}\right)$ & 33 & 5.88 & .927 \\
& Valuation - Bearish evaluation $\left(D_{4}\right)$ & 34 & 2.53 & .992 \\
5 & Risk - Bullish evaluation $\left(U_{5}\right)$ & 35 & 3.31 & 1.549 \\
& Risk - Bearish evaluation $\left(D_{5}\right)$ & 35 & 4.09 & 1.579 \\
6 & Management - Bullish evaluation $\left(U_{6}\right)$ & 34 & 3.88 & 1.533 \\
& Management - Bearish evaluation $\left(D_{6}\right)$ & 34 & 4.09 & 1.164 \\
\hline
\end{tabular}

* Question on a 1-7 Likert scale (1-strongly disagree to 7-strongly agree) that the narrative attribute contains compelling evidence that the stock price will go up (positive), and that it contains compelling evidence that the stock price will go down (negative).

Nevertheless, there was variance in how the control group participants viewed the specific attributes. The Analyst Note attribute was seen as more bearish than bullish, as was the Risk attribute and to a lesser degree the Management attribute. In contrast, they viewed the Investment Thesis, Economic Moat, and Valuation attributes as more bullish than bearish. This variance in participants' interpretation of the different attributes supports the calculation of separate baseline evaluations for each attribute.

The Effect of Leanings on Attribute Evaluations. We modeled the effect of leanings using data from the 190 participants in the choice condition. We find that emerging leanings have a 
significant influence on both bullish (Model in Equation 1: $R^{2}=.50 ; F(3,186)=62.20, p<$

.01 ) and bearish evaluations (Model in Equation 2: $\left.R^{2}=.53 ; F(3,186)=69.36, p<.01\right) .{ }^{3}$ The detailed results are presented in Figure 2.

FIGURE 2- Experiment 1: Effect of Prior Leaning on Positive and Negative Evidence in Narrative Attributes Provided in an Investor Report*

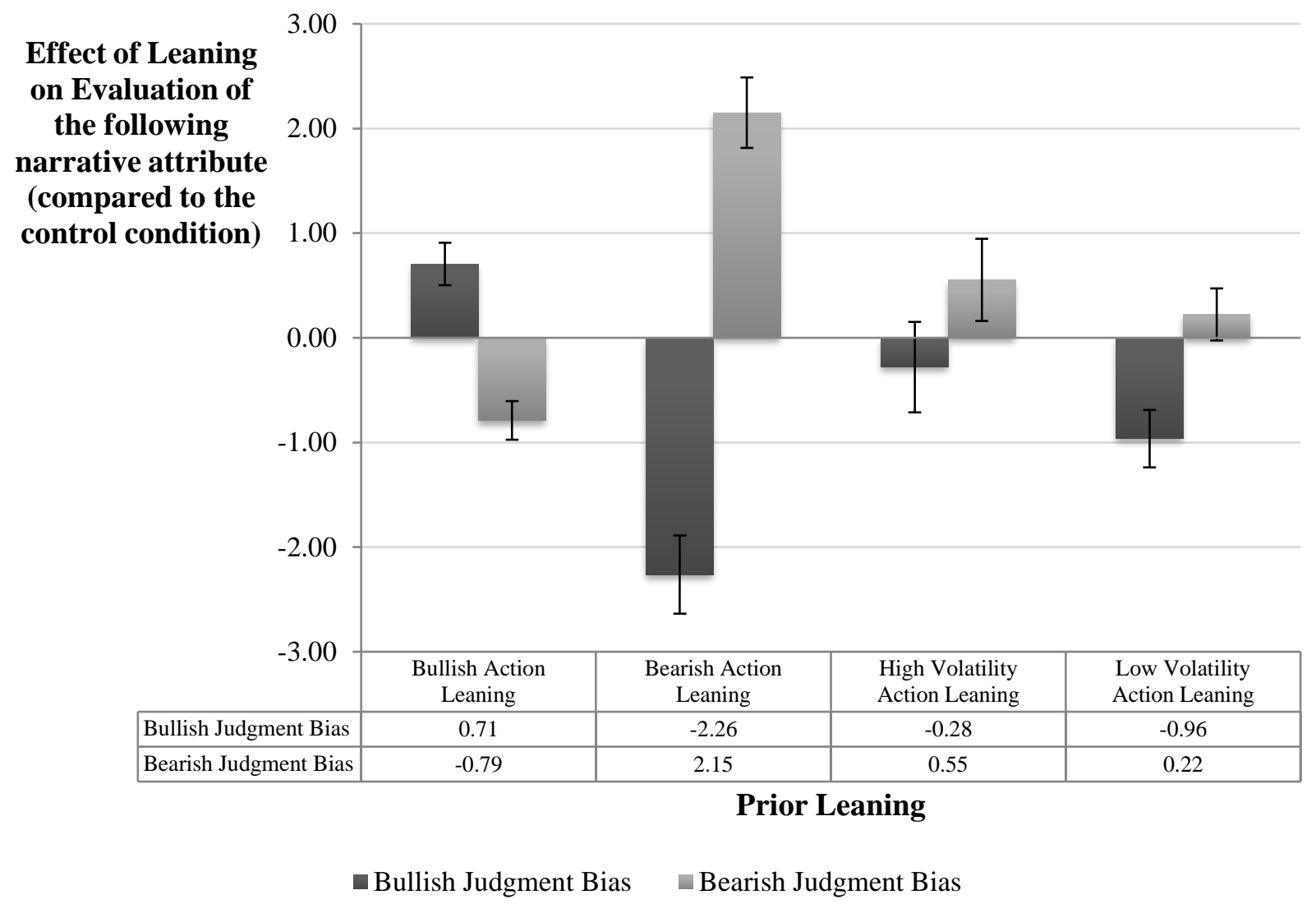

* Note: Error bars represent $95 \%$ confidence intervals around mean of $\beta_{U, k}$ and $\beta_{D, k}$.

\footnotetext{
${ }^{3}$ To account for the correlation between $\bar{D}_{\text {Neg }}^{i}$ and $\bar{D}_{\text {Pos }}^{i}$ We have also estimated models where $\bar{D}_{\text {Neg }}^{i}$ is included as a predictor is in Equation 1, and $\bar{D}_{P O S}^{i}$ is included in Equation 2. We found no change in the significance of effects of leanings on subsequent attributes. We present the results from models in Equations 1 and 2 for ease of interpretation.
} 
Bullish Leaning. When participants had a bullish leaning (i.e., they expected the stock price to increase) - a condition that was present in $45.58 \%$ of leanings - the interpretation of the next attribute was significantly biased, with participants viewing it as more supportive of an increase in the stock price than was warranted $\left(\beta_{U, B U}=.71 ; t(186)=6.86, p<.01\right)$ and less supportive of a price decrease than was warranted $\left(\beta_{D, B E}=-.79 ; t(186)=-8.44, p<.01\right)$, as determined by the attribute baselines obtained from participants in the control condition. Put differently, participants who had a bullish leaning distorted their evaluation of subsequent analyst information to be more bullish and less bearish than was warranted by the true nature of the information.

Bearish Leaning. When participants had a bearish leaning (i.e., they expected the stock price to decrease; $16 \%$ of leanings), their interpretation of the next attribute was also biased. Specifically, participants viewed the next attribute as providing less evidence for a price increase $\left(\beta_{U, B E}=-2.26 ; t(186)=-11.95, p<.01\right)$ and more evidence for a price decrease $\left(\beta_{D, B E}=\right.$ $2.15 ; t(186)=12.61, p<.01)$ than was warranted. Thus, when participants developed a bearish leaning, they biased their interpretation of the narrative attribute such that it was perceived as both less bullish and more bearish.

High Volatility Leaning. Participants could also have a leaning towards high volatility, such that they expected the stock price to move significantly, either up or down (with uncertain direction; $9.89 \%$ of leanings). Given this leaning, participants could have supported it by interpreting a subsequent attribute as providing more compelling evidence for both bullish and bearish actions. Yet, whereas we did find that participants interpreted the narrative attribute as more bearish than those in the control condition $\left(\beta_{D, H V}=.55 ; t(186)=2.78, p<.01\right)$, these participants did not bias their bullish evaluations $\left(\beta_{U, H V}=-.28 ; t(186)=-1.28, p=.20\right)$. 
This suggests that participants leaning toward high volatility, when evaluating this investment report, mostly supported their leaning by biasing their bearish evaluations of subsequent narrative attributes.

Low Volatility Leaning. Finally, participants could have had a leaning toward low volatility, such that they expected the stock price not to move significantly from its current price ( $28.53 \%$ of leanings). These participants could have supported their leaning by judging the narrative attribute as being both less bullish and less bearish. Whereas we did find that these participants judged the narrative attributes to be less bullish than participants in the control condition $\left(\beta_{U, L V}=-.96 ; t(186)=-6.93, p<.01\right)$, they did not bias their bearish evaluations to be less bearish than control participants $\left(\beta_{D, L V}=.22 ; t(186)=1.77, p=.08\right)$. This suggests that participants expecting low volatility, when evaluating this investment report, mostly supported their leaning by biasing bullish evaluations.

\section{Discussion}

In the present experiment, we have found that financial investment leanings did influence how new information was interpreted. For respondents with directional leanings (i.e., bullish or bearish), subsequent attributes were interpreted as providing evidence supporting their particular leanings. Moreover, when the leaning was bearish (i.e., the stock price was expected to decrease), the magnitude of the bias was approximately twice as large as it was for bullish leanings. Those who leaned toward the high volatility action supported their leaning by biasing their bearish evaluations (but not their bullish ones), whereas those who leaned toward low volatility action did the opposite. 


\title{
EXPERIMENT 2 - PREDECISIONAL DISTORTION IN FINANCIAL REPORTS
}

\author{
Stimuli and Measures
}

The scenario was nearly identical to that of Experiment 1, except participants were assigned an investment report for one of six companies as part of a between-subjects design. Specifically, participants were randomly assigned to read information about one of the following companies: Advanced Auto Parts (AAP), Best Buy (BBY), GILEAD Sciences (GILD), Morgan Stanley (MS), Oracle (ORCL), or Twitter (TWTR). We chose these particular companies because they differed markedly from each other in terms of their size, recent profitability, share price, and industry.

After reading an overview of their assigned company, participants read and evaluated six pieces of information (narrative attributes) from the analyst report. As in Experiment 1, each attribute was shown on a separate screen, and the attributes were presented in the same order (i.e., Analyst Note, Investment Thesis, Economic Moat, Valuation, Risk, and Management). After reading each attribute, participants answered the same two bullishness and bearishness evaluation statements and reported their current leaning. As in Experiment 1, four leanings were offered as choices to participants. The wording was, however, slightly altered to provide a clearer description of each alternative: 1) "I believe the stock will go up, from its current price (bullish)", 2) "I believe the stock will go down, from its current price (bearish)", 3) "I believe the stock will move significantly from its current price. The stock could move up, or it could down, but it will move (high volatility)", and 4) "I believe the stock will not move significantly from its current price (low volatility).” 
Control Condition. To obtain bullish and bearish evaluations unbiased by leanings, participants in a separate control condition judged one narrative attribute, for each of the companies, in one of six between-subject conditions. The six conditions ensured that not only that each of six companies was evaluated on each of the six narrative attributes (e.g., order 1: Analyst Note: AAP, Investment Thesis: BBBY, Economic Moat: GILD, Valuation: MS, Risk: Oracle, Management: TWTR), but also that each company was evaluated at each of the six positions (e.g., $\left.1^{\text {st }}, 2^{\text {nd }}, \ldots, 6^{\text {th }}\right)$. As these evaluations were presented in one of six orders, between subjects and without an emerging leaning, their interpretations could not be influenced by any bias. As in Experiment 1, the mean evaluation across all control participants was used to provide the unbiased bullish and bearish evaluation measures.

Participants and Procedures

To identify participants who had sufficient financial literacy and understanding of the market, we again administered the Advanced Financial Literacy scale (Rooij et al., 2011) to participants on Amazon Mechanical Turk. Specifically, we recruited an additional 4465 participants located in exchange for $\$ 0.15$. As in Study 1, participants who correctly answered 8 or more of the 11 advanced financial literacy questions and reported owning an investment account were qualified to become part of the investment choice study. Of all the participants who took the qualification survey, 1256 qualified and were offered the opportunity to participate in a follow-up survey on investments in exchange for an additional payment of $\$ 1$. Of these 
participants, 1117 chose to do so and completed the study with 583 participants in one of the six choice conditions, and 484 for the control condition. ${ }^{4}$

Results

We modeled the effect of leanings using the between-effects models described in equations 1 and 2 on the data from the 583 participants in the choice condition. As expected, we continue to find that leanings have a significant on both bullish (Model in Equation $1: R^{2}=.29 ; F(3,579)=$ $78.75, p<.01$ ) and bearish evaluations (Model in Equation 2: $R^{2}=.23 ; F(3,186)=$ 59.99, $p<.01$ ) across all six companies. The detailed results are presented in Figure 3.

Leaning: Bullish. When participants had a bullish leaning (33.86\% of the leanings), the interpretation of the next attribute was significantly biased. Specifically, participants made interpretations such that the narrative attribute provided more compelling evidence of an increase in the stock price than $\left(\beta_{U, B U}=.60 ; t(579)=8.80, p<.01\right)$ and less compelling evidence of a decrease in the stock price $\left(\beta_{D, B E}=-.60 ; t(579)=-8.85, p<.01\right)$. That is just as in Study 1, participants who had a bullish leaning biased their evaluation of subsequent analyst information to provide bullish (bearish) evaluations that reflect the attribute to contain evidence that is more (less) compelling of an increase (decrease) in stock price.

Leaning: Bearish. When participants had a bearish leaning (27.62\% of leanings), the bullish and bearish evaluations of the next attribute were both biased. As in Study 1, the next attribute was seen as providing evidence that is less compelling as supporting an increase in the

\footnotetext{
${ }^{4}$ This included 291 participants from Study 1, but we ensured that none of these participants were assigned to the choice condition for Morgan Stanley - the company they had previously seen. Including past participation as a predictor does not affect our results.
} 
stock price than believed participants in the control condition $\left(\beta_{U, B E}=-1.10 ; t(579)=\right.$ $-14.43, p<.01)$. Further, it was also seen to provide more compelling evidence for a decrease in stock price $\left(\beta_{D, B E}=.84 ; t(579)=11.14, p<.01\right)$. As such once participants had a bearish leaning, they biased their bullish statement evaluations such that the attribute provided less compelling regarding a bullish action, and simultaneously more compelling for a bearish action. This is entirely consistent with the results of Experiment 1.

FIGURE 3 - Experiment 2: Effect of Prior Leaning on Positive and Negative Evidence in Narrative Attributes Provided in an Investor Report*

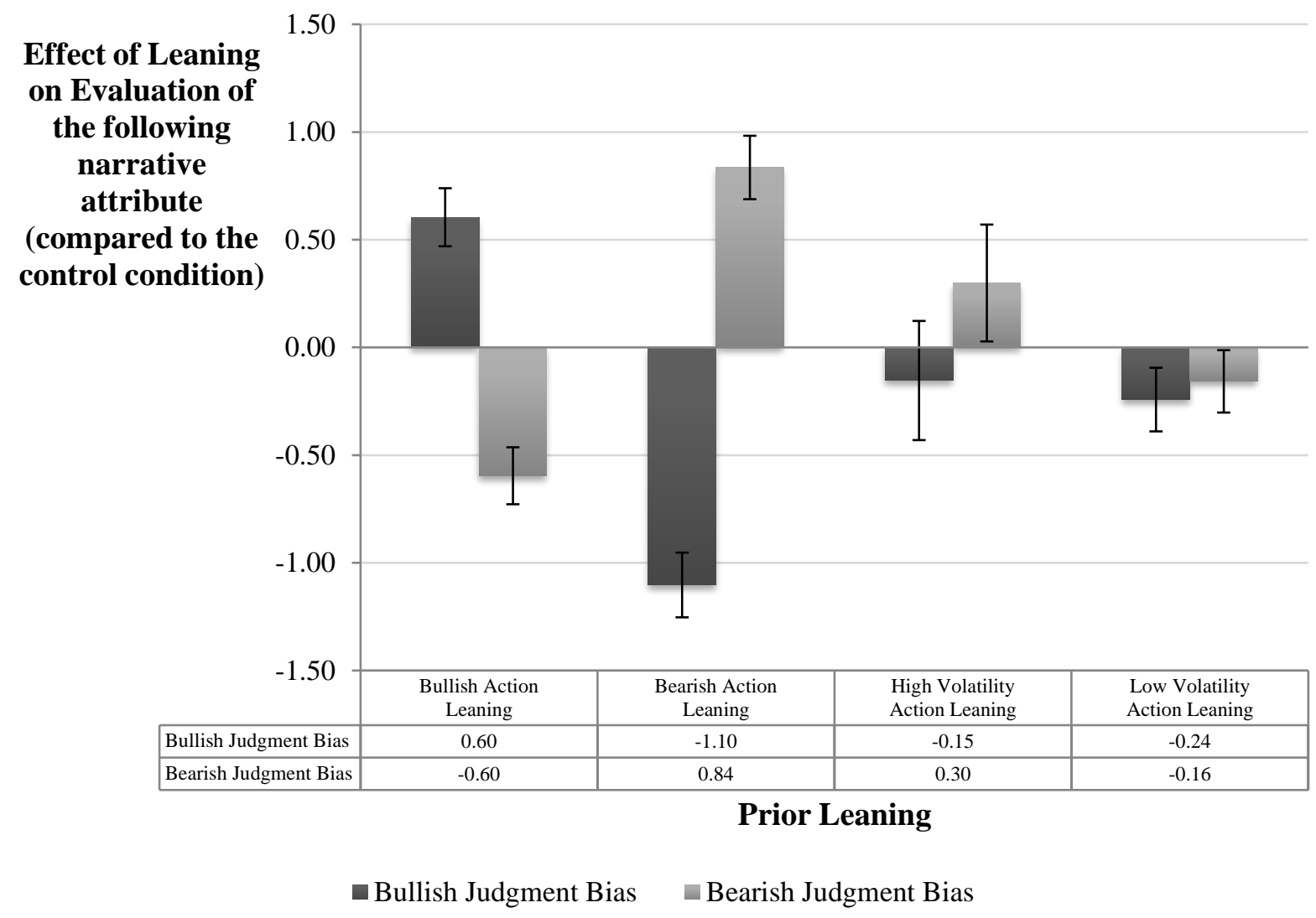

* Note: Error bars represent $95 \%$ confidence intervals around mean of $\beta_{U, k}$ and $\beta_{D, k}$. 
Leaning: High Volatility. Participants who a leaning on high volatility $(8.47 \%$ of leanings), could have supported it by judging the narrative attribute as providing more compelling evidence for both bullish and bearish actions. As in Study 1, we did find that participants judged the narrative attribute as providing more compelling than participants for a bearish action than those in the control condition $\left(\beta_{D, H V}=.30 ; t(579)=2.16, p=.03\right)$ and we failed to find support for any bias of their bullish evaluations $\left(\beta_{U, H V}=-.15 ; t(579)=\right.$ $-1.09, p=.28$ ). This provides converging evidence that those with a high volatility leaning supported it by biasing their bearish evaluations and not bullish evaluations.

Leaning: Low Volatility. Finally, participants could have a leaning on low volatility (30.05\% of leanings) and could have supported their leaning by judging the narrative attribute as being less compelling for both bullish and bearing actions. We found evidence that both occurred. Specifically, participants judged both the bullish evidence to be less compelling than participants in the control condition $\left(\beta_{U, L V}=-.24 ; t(579)=-3.22, p<.01 ; \beta_{D, L V}=\right.$ $-16 ; t(579)=-2.14, p=.03)$. This is mostly consistent with the results of Study 1 , where we had only found evidence of bias for the bullish evidence.

Robustness Checks. We have found in both studies that readers of analyst reports bias their evaluations of new information to be consistent with their leanings. In Experiment 2, we had data collected for six companies instead of just one, and the above analyses were agnostic to which company was being judged (for simplicity). We have also tested the models above while including dummy variables for each company to company heterogeneity.

Using F-tests to investigate the incremental explanatory power added from including these predictors, we find marginal evidence that difference existing in bias in bullish evaluation bias depending on the company $(F(8,574)=.38, p=.07)$ and for bearish evaluation bias 
$(F(8,574)=.31, p=.04)$. Examination of contrast suggests that both the bullish and bearish bias was robust across for all companies at a level of $\mathrm{p}<.05$ when the participants had a bullish or bearish leaning. No company seemed to have such distinct patterns that their results influence those obtained by the aggregate analyses and represent an omitted variable bias. Further, as in Study 1, we fail to find evidence that the correlation between $\bar{D}_{N e g}^{i}$ and $\bar{D}_{P o s}^{i}$ is responsible for our effects. Specifically when we estimated models where $\bar{D}_{\text {Neg }}^{i}$ is added as a predictor is to Equation 1, and $\bar{D}_{P o s}^{i}$ is added to Equation 2, we found no change in the significance of effects of the leanings.

\section{GENERAL DISCUSSION}

With unprecedented access to trading strategies and information previously only available to institutional investors, retail investors consuming analyst reports are not subject to kinds of predecisional biases that are typically not seen in the choices they face outside of investment settings. Building on recent methodology on pro-leader and anti-trailer predecisional distortion in the context of multi-alternative choices (Blanchard et al. 2014; DeKay et al. 2014; Miller 2014), we illustrate the importance of considering the kind of leanings that emerge as investors peruse analyst reports. We have argued that such investors reading such reports for a particular underlying (i.e., stock) could develop one of four leanings: bullish (taking a position that profits if the stock price increases), bearish (taking a position that profits if the stock price decreases), high volatility (taking a position that profits if the stock price either increases or decreases) or low volatility (taking a position that profits if the stock price does not increase or decrease). Each of these leanings predicted a different type of predecisional distortion of new information about the company, and our results supported the existence of such differences. The 
differences between leanings regarding whether predecisional distortion influences an unduly positive or negative evaluation of subsequent information highlights the importance of understanding the nature of the options being studied.

Our work contributes to the investor and predecisional biases literature. We investigate whether leanings impact how new information is interpreted in the context of individual investors reviewing analyst reports - a setting in which predecisional distortion has never before been examined despite the potential for substantial consequences for both individuals as well as for financial markets (Du and Osmonbekov 2019). Thus, whereas prior work has recognized that predecisional distortion may occur even among individuals with high levels of domain expertise (e.g., professional auditors, see Wilks 2002) and that investors may be biasing information in analyst reports based on prior beliefs (Hirst, Koonce, \& Simko 1995), our analyses provide a first investigation about how biases emerge as investors read the reports and process the information. Indeed, in prior investigations of biases in the reading of analyst reports, the reports were presented in complete form - having access to all the information in the report at once. As such, the authors could observe the decision process that led investors to reach their valuation - only the outcome. It would be interesting for future research to apply the predecisional distortion paradigm proposed herein to investigate biases emerging through the reading of other sources of financial information such as earning announcements (Lim, Tuli, Dekimpe 2018).

Our findings also relate to prior research showing that investors tend to exhibit a negativity bias, whereby they weigh negative information more heavily than positive information (Young 2009). We do find greater overall bias for those who adopt a bearish leaning than for those who adopt any other leaning, suggesting that there is something inherently bias inviting about a bearish leaning. However, for bullish, bearish, and low volatility leanings, we find that 
the bias in investor evaluations is roughly symmetric. For example, those leaning toward buying a stock bias the information to be more bullish than it really is, and they also bias the information to be less bearish than it really is. Likewise, those leaning toward selling a stock bias the information to be more bearish than it really is, and the magnitude of this bias is the same as the magnitude of their tendency to see the information as less bullish than it really is. In sum, we do find that for high volatility leanings, most of the bias occurs in the bearish evaluations, which could be viewed as a form of negativity bias, and which fits with the idea that investors and analysts use financial information differently depending on the decision goal (Young 2009).

Prior research has also found that most trading volume is associated with directional investments, not volatility trades (Lakonishok et al. 2007). Consistent with this, we found that directional leanings (i.e., either a bullish leaning or a bearish leaning) represented a majority (62\%) of leanings in our experiment. But we also found that directional leanings had the largest magnitude of bias to support them, which may help explain why directional positions are more common. That is, when an investor leans toward a directional action, they bias the evidence to carry them through to action to a greater degree than when they lean toward a volatility action. Via qualifications in online panels, we are able to obtain data for individuals who have expertise in the domain and sufficient financial literacy, contributing to a growing literature on the importance of expertise in financial decision-making processes (Ganzach 2000; Hung-Tong Tan \& Yates 2002; Moore et al., 1999; Wilks 2002) and marketing (Chung and Low 2017). We thus also contribute to a growing literature that tries to characterize investment behaviors on the basis of financial literacy (Van Rooij, Lusardi, \& Alessie 2011).

Although outside the scope of the current work, future research may seek to investigate how conditioning on the type of leaning can be used to reveal novel patterns in information 
interpretation, novel patterns that in retrospect indicate decision-makers using distortion to support emerging leanings. There are many settings where progress toward making a choice is not necessarily aided by biasing new information to favor the focal alternative. Examples include alternative treatments for a disease (e.g., Nurek, Kostopoulou, \& Hagmayer 2014), where the focal treatment may be unappealing because of side effects, so the leaning might be a non-focal alternative. Or as in the cases above, the situation might involve just one focal alternative and how to act regarding it. There are many social situations where reaction to a person might be influenced by distortion to support whichever action one is leaning toward based factors such as early indications of the person's motivations. Other examples include assessing guilt or innocence of single entity, including which particular level of a crime to charge the person with (Holyoak \& Simon 1999). Our work thus contributes to a growing body of literature that investigates preference construction models beyond contexts where accumulating preference for one option necessarily affects the evaluation of information about another (Turner et al. 2018).

\section{References}

Albright, D. (2018). Renaissance of the retail investor: Individual investors are about to play a much bigger role in the investment industry. Real Assets Advisor 5 (4). Retrieved on November 28, 2019, at https://irei.com/publications/article/renaissance-retail-investor-individual-investorsplay-much-bigger-role-investment-industry/

Blair, S. (2019) "How Lacking Control Drives Fluency Effects in Evaluative Judgment," forthcoming at Organizational Behavior and Human Decision Processes.

Blanchard, S. J., Carlson, K. A., \& Meloy, M. G. (2014). Biased predecisional processing of leading and nonleading alternatives. Psychological Science, 25(3), 812-816.

Bond, S. D., Carlson, K. A., Meloy, M. G., Russo, J. E., \& Tanner, R. J. (2007). Information distortion in the evaluation of a single option. Organizational Behavior and Human Decision Processes, 102(2), 240-254.

Brownstein, A. L. (2003). Biased predecision processing. Psychological bulletin, 129(4), 545. 
Carlson, K. A., \& Guha, A. (2011). Leader-focused search: The impact of an emerging preference on information search. Organizational Behavior and Human Decision Processes, 115(1), 133-141.

Carlson, K. A., \& Pearo, L. K. (2004). Limiting predecisional distortion by prior valuation of attribute components. Organizational Behavior and Human Decision Processes, 94(1), 48-59.

Chaxel, A. S. (2015). How do stereotypes influence choice? Psychological Science, 26(5), 641645.

Chaxel, A. S., Russo, J. E., \& Kerimi, N. (2013). Preference-driven biases in decision makers' information search and evaluation. Judgment and decision making, 8(5), 561-576.

Chung, T. S., \& Low, A. (2017). The impact of investor impatience and environmental turbulence on myopic marketing management and stock performance. International Journal of Research in Marketing, 34(3), 660-677.

DeKay, M. L. (2015). Predecisional Information Distortion and the Self-Fulfilling Prophecy of Early Preferences in Choice. Current Directions in Psychological Science, 24(5), 405-411.

DeKay, M. L., Patiño-Echeverri, D., \& Fischbeck, P. S. (2009). Distortion of probability and outcome information in risky decisions. Organizational Behavior and Human Decision Processes, 109(1), 79-92.

DeKay, M. L., Miller, S. A., Schley, D. R., \& Erford, B. M. (2014). Proleader and antitrailer information distortion and their effects on choice and postchoice memory. Organizational Behavior and Human Decision Processes, 125(2), 134-150.

Du, D., \& Osmonbekov, T. (2019). Direct effect of advertising spending on firm value: Moderating role of financial analyst coverage. International Journal of Research in Marketing.

Erford, B. M. (2014). Investigating Patterns and Differences in Proleader and Antitrailer Information Distortion (Doctoral dissertation, The Ohio State University).

Ganzach, Y. (2000). Judging risk and return of financial assets. Organizational Behavior and Human Decision Processes, 83(2), 353-370.

Gonzalez, R. (1994). When Words Speak Louder Than Actions: Another's Evaluations Can Appear More Diagnostic Than Their Decisions. Organizational Behavior and Human Decision Processes, 58(2), 214-245.

Hirst, D. E., Koonce, L., \& Simko, P. J. (1995). Investor reactions to financial analysts' research reports. Journal of Accounting Research, 33(2), 335-351. 
Holyoak, K. J., \& Simon, D. (1999). Bidirectional reasoning in decision making by constraint satisfaction. Journal of Experimental Psychology: General, 128(1), 3-31.

Lewis, D., \& Gill, T. (2016). Is there a mere categorization effect in investment decisions?. International Journal of Research in Marketing, 33(1), 232-235.

Lim, L. G., Tuli, K. R., \& Dekimpe, M. G. (2018). Investors' evaluations of price-increase preannouncements. International Journal of Research in Marketing, 35(3), 359-377.

Lord, Charles G.; Ross, Lee; Lepper, Mark R. (1979), "Biased assimilation and attitude polarization: The effects of prior theories on subsequently considered evidence", Journal of Personality and Social Psychology, 37(11), 2098-2109.

Lusardi, A. (2012). Numeracy, financial literacy, and financial decision-making, NBER Working Paper No. 17821, February, 2012, JEL No. D91.

McGrath, C. (2017). 80\% of equity market cap held by institutions. Pensions and Investments Online. Retrieved on November 28 (2019) from https://www.pionline.com/article/20170425/INTERACTIVE/170429926/80-of-equity-marketcap-held-by-institutions

Miller, S. A., DeKay, M. L., Stone, E. R., \& Sorenson, C. M. (2013). Assessing the sensitivity of information distortion to four potential influences in studies of risky choice. Judgment and Decision Making, 8(6), 662.

Miller, S. A. (2014). Assessing the Sensitivity, Composition, and Effects of Information Distortion (Doctoral dissertation, The Ohio State University).

Moore, D. A., Kurtzberg, T. R., Fox, C. R., \& Bazerman, M. H. (1999). Positive illusions and forecasting errors in mutual fund investment decisions. Organizational Behavior and Human Decision Processes, 79(2), 95-114.

Nurek, M., Kostopoulou, O., \& Hagmayer, Y. (2014). Predecisional information distortion in physicians' diagnostic judgments: Strengthening a leading hypothesis or weakening its competitor? Judgment and Decision Making, 9(6), 572.

Poterba, J., Venti, S., \& Wise, D. A. (2007). The changing landscape of pensions in the United States (No. w13381). National Bureau of Economic Research.

Russo, J. E., Carlson, K. A., \& Meloy, M. G. (2006). Choosing an inferior alternative. Psychological Science, 17(10), 899-904.

Russo, J. E., Medvec, V. H., \& Meloy, M. G. (1996). The distortion of information during decisions. Organizational Behavior and Human Decision Processes, 66(1), 102-110. 
Tan, H. T., \& Yates, J. F. (2002). Financial budgets and escalation effects. Organizational Behavior and Human Decision Processes, 87(2), 300-322.

Turner, B. M., Schley, D. R., Muller, C., \& Tsetsos, K. (2018). Competing theories of multialternative, multiattribute preferential choice. Psychological Review, 125(3), 329.

Westen, D., Blagov, P. S., Harenski, K., Kilts, C., \& Hamann, S. (2006). Neural bases of motivated reasoning: An fMRI study of emotional constraints on partisan political judgment in the 2004 US presidential election. Journal of Cognitive Neuroscience, 18(11), 1947-1958.

Wilks, T. J. (2002). Predecisional distortion of evidence as a consequence of real-time audit review. The Accounting Review, 77(1), 51-71.

Van Rooij, M., Lusardi, A., \& Alessie, R. (2011). Financial literacy and stock market participation. Journal of Financial Economics, 101(2), 449-472.

Young, S. M. (2009). The effect of perceived uncertainty on analysts' recommendations and earnings forecasts. Review of Behavioral Finance, 1(1-2), 62-82. 


\section{Appendix A - Investor Report for Morgan Stanley}

Analyst Note. While Morgan Stanley reported disappointing third-quarter numbers, we still believe in the company's core strategy and that there's optionality in regard to the company's fixed-income trading business and capital returns. The company's Institutional Securities and Investment Management segments led the company to a $16 \%$ decrease in net revenue from the previous year, excluding debt valuation adjustments. The underperforming revenue lines were similar to other investment banking firms with fixed-income trading, underwriting, and revenue tied to investment performance being the primary culprits. The wealth management segment remained fairly steady with a net revenue decline of only $4 \%$. We don't anticipate making a material change in our fair value estimate for narrow-moat Morgan Stanley, and believe that its shares are starting to look attractive.

We believe that Morgan Stanley's measured approach to scaling its fixed-income and commodities trading business is reasonable in the current environment. The company already has shrunk its fixed-income risk-weighted assets by more than half over the past several years, so we wouldn't accuse management of sitting on its hands through the changes in the credit trading landscape. The majority of its physical commodities operations should also be gone by the end of this year. It's true that the company's fixed-income trading business after this restructuring still hasn't proven itself to be a consistently high return on capital business, but the potential for market share gains over the next year as competitors scale back their businesses is worth the wait, in our opinion. Moreover, we continue to believe that there's little better use for the capital. With Morgan Stanley being arguably overcapitalized and U.S. regulators still not allowing most of the large U.S. banks to return more than their projected net income, capital freed up is likely just to sit in return, hampering excess liquidity.

Investment Thesis. There are still multiple questions surrounding Morgan Stanley's rebirth as a financial holding company regulated by the Fed and the imposition of more stringent regulations that will likely reduce returns on equity. Changes on the revenue front include principal investment activity being limited, proprietary trading being prohibited, selling of physical commodity operations, and rules increasing the transparency of OTC derivatives that could decrease sales margins. Regulatory capital and liquidity requirements are also increasing by a multiple. The approximate doubling of Morgan Stanley's equity base and shares and related halving of leverage since the end of 2007 puts the company on firmer financial footing. However, it also makes it nearly impossible for the company to achieve its historical levels of returns on capital and earnings per share.

This regulatory situation forces Morgan Stanley to be more focused on risk-adjusted returns on capital. For each of Morgan Stanley's segments, we're concentrating on different value drivers. In institutional securities, we're focusing on Basel III risk-weighted assets, as this is the most capital-intensive segment with the greatest opportunity for capital optimization. A selective streamlining of the company's fixed-income business could improve returns on capital allocated to the business, even if the absolute level of revenue doesn't grow.

In wealth management, we're focused on operating margins; and in 2014 wealth management margins were already at $20 \%$. We believe management's $22 \%$-plus target for 2015 onward is achievable. Longer term, we estimate that the effect of more normalized interest rates on margin loans and bank assets should add $\$ 1.5$ billion of net interest income to this segment. Owing to the high incremental margins on the net interest income, overall wealth management margins should consequently expand 2 to 4 percentage points.

In investment management, scale is key. After dismal results from 2008 through 2012, this segment is finally making returns above its cost of capital. That said, the segment needs to be several times larger to be material to the company's overall value.

Economic Moat. Investment banking moats are primarily built on the network effect and intangibles. A large securities distribution platform and extensive web of relationships allow an investment bank to more properly price and place securities. A strong reputation makes it more likely that an investment bank will be selected as a 
bookrunner, capturing more of the profits from an underwriting deal, and gives the firm an early opportunity to hire top revenue-generating talent.

We asses Morgan Stanley as having a narrow economic moat. Being one of the largest financial institutions by both headcount and global reach means that the company has a competitive advantage derived from the personal networks of its employees and financial product distribution channels to garner transaction mandates. The company's reputation, developed over the decades, for pricing transactions in a way that benefits both sellers and buyers puts the company at the top of managements' minds when contemplating an investment banking deal. Its relatively high revenue production per employee gives evidence that its brand makes the company an employer of choice when financial talent is seeking a new home.

Valuation. The current price is 32.72. Our fair value estimate for Morgan Stanley is $\$ 38$ per share. This implies a forward price/earnings ratio of 11.7 times and a price/tangible book ratio of 1.3 times. Earnings from our last valuation update and higher-than-expected trading revenue were offset by a slightly lower client asset growth assumption and a decrease in our long-term leverage assumption to about 13 times from 14 times. We're projecting a net revenue compound annual growth rate of about 3.3\% during the next five years. Much of our projected revenue increase comes from asset management and net interest income. We forecast AUM growing at a normalized rate of approximately $4.5 \%$ from market appreciation. We project net interest income eventually growing to nearly $\$ 5$ billion from $\$ 1.7$ billion in 2014. The increase will come from the effect of higher, more normalized rates on wealth management and bank assets, a greater proportion of the company's bank portfolio in loans instead of available for sale securities, and the decrease of the net interest income drag caused by borrowing at high long-term rates to fund an outsized liquidity buffer. For trading and investment banking revenue, we're forecasting 4\%-5\% annual growth after rebasing. We model across-a-cycle operating margins of about $23 \%$. This includes a $48 \%$ compensation ratio. The higher-than-long-run historical compensation ratio is from a larger proportion of revenue coming from the wealth management business. We're projecting noncompensation expenses growing $3.5 \%$ annually off of a more normalized base excluding certain legal charges of around 10 billion. We calculate Morgan Stanley earning a return of nearly $12 \%$ on tangible common equity in the medium term, $9.5 \%$ on total common equity, and a long-term gross leverage ratio of 13 times. Finally, we use a cost of equity of $9 \%$ in our discounted cash flow model.

Risk. We believe Morgan Stanley's primary concern is finding the right balance in its fixed-income and commodities business. Several years ago, the company's strategy toward its fixed-income and commodities business was gaining market share and shifting its product mix toward more client flow products like interest rates and foreign exchange and away from credit and commodities. More recently, it appears that the rates business isn't performing as hoped, the company's entire physical commodities business may be sold, and returns on segment capital are being emphasized over market share gains. This business is likely management's largest headache. That said, the fixed-income and commodities business averaged around $15 \%$ of net revenue over the last four years, so whether its returns on capital improve or decrease, it should only be a marginal positive or negative to consolidated company returns.

Management. James P. Gorman has been CEO and president of Morgan Stanley since the beginning of 2010. He has been with the firm since 2006 and held responsibilities associated with the company's wealth management, investment management, operations, and corporate strategy. Before joining Morgan Stanley, he was an executive in Merrill Lynch's private client business. Historically, Morgan Stanley earned returns above its cost of capital. Recently, the company survived a couple of instances where some questioned its viability as a going concern, and took a transformative step with the expansion of its wealth management business, a move that should position it well for the current regulatory environment. We believe these are laudable management achievements, but currently--and in the near future--we don't foresee large excess returns on capital. The capital base has grown dramatically, and expenses remain high. Therefore, we believe the company's stewardship of shareholder capital is Standard. 


\section{Appendix B - Advanced (Financial) Literacy Questions from van Rooik et al. (2011)}

1. Which of the following statements describes the main function of the stock market?

a) The stock helps to predict stock earnings

b) The stock market results in an increase in the price of stocks

c) The stock market brings people who want to buy stocks together with those who want to sell stocks

d) None of the above

e) Do not know

f) I refuse to answer

2. Which of the following statements is correct? If somebody buys the stock of firm B in the stock market:

a) He owns a part of firm B

b) He has lent money to firm $B$

c) $\mathrm{He}$ is liable for firm B's debts

d) None of the above

e) Do not know

f) I refuse to answer

3. Which of the following statements is correct?

a) Once one invests in a mutual fund, one cannot withdraw the money the first year

b) Mutual funds can invest in several assets, for example invest in stocks and bonds

c) Mutual funds pay a guaranteed rate of return which depends on their past performance

d) None of the above

e) Do not know

f) I refuse to answer

4. Which of the following statements is correct? If somebody buys a bond of firm B:
a) He owns a part of firm $B$
b) He has lent money to firm $B$
c) He is liable for firm B's debts
d) None of the above
e) Do not know
f) I refuse to answer

5. Considering a long time period (for example 10 or 20 years), which asset normally gives the highest return?
a) Savings account
b) Bonds
c) Stocks
d) Do not know

e) I refuse to answer

6. Normally, which asset displays the highest fluctuations over time?
a) Savings accounts
b) Bonds
c) Stocks
d) Do not know
e) I refuse to answer

7. When an investor spreads his money among different assets, does the risk of losing money:
a) Increase
b) Decrease
c) Stay the same
d) Do not know
e) I refuse to answer

8. If you buy a 10-year bond, it means you cannot sell it after 5 years without incurring a major penalty. True or false?
a) True
b) False
c) Do not know
d) I refuse to answer

9. Stocks are normally riskier than bonds. True or false?
a) True
b) False
c) Do not know
d) I refuse to answer

10. Buying a company stock usually provides a safer return than a stock mutual fund. True or false?
a) True
b) False
c) Do not know
d) I refuse to answer

11. If the interest rate falls, what should happen to bond prices?
a) Rise
b) Fall
c) Stay the same
d) None of the above
e) Do not know
f) Refusal 